\title{
Proceeding
}

Supplementary Issue: Spring Conferences of Sports Science. Costa Blanca Sports Science Events, 14-15 June 2019. Alicante, Spain.

\section{Multilateral training improves physical fitness and fatigue perception in cancer patients}

\author{
STEFANIA CATALDI, FRANCESCA LATINO, GIANPIERO GRECO , FRANCESCO FISCHETTI \\ Department of Basic Medical Sciences, Neuroscience and Sense Organs, School of Medicine, University of \\ Study of Bari, Italy
}

\begin{abstract}
Cancer patients bring with them physiological and psychological side effects and physical activity is emerging as a major tool to improve their quality of life and survival. Therefore, the purpose of this study was to investigate the effect of 8-week multilateral training program on perceived fatigue, lower back flexibility, balance and task specific functional mobility in cancer patients. Twenty participants (52.6 \pm 17.1 years) were pair-matched based on age and then randomly assigned to an experimental group $(n=10)$ that performed a progressive training of cardiorespiratory, resistance, flexibility and postural education exercises ( 60min, $2 d \cdot w k-1)$, or a wait-list control group $(n=10)$. Measures pre-intervention and post-intervention included psychological and physiological measurements. After intervention, significant improvements $(p<0.01)$ were detected in experimental group for the perceived fatigue, trunk lateral flexibility test (right and left sides), stork balance stand test (right and left sides) and 30 seconds chair stand test. Findings suggest that multilateral training program may improve the physical fitness and reduce perceived fatigue in cancer patients providing an important support to deal with physiological and psychological side effects. In addition, this multilateral approach may actually prevent physical inactivity, muscle wasting, and loss of energy in special populations. Keywords: Physical fitness; Special population; Cancer-related fatigue; Adapted physical activity.

\section{Cite this article as:}

Cataldi, S., Latino, F., Greco, G., \& Fischetti, F. (2019). Multilateral training improves physical fitness and fatigue perception in cancer patients. Journal of Human Sport and Exercise, 14(4proc), S916-S926. doi:https://doi.org/10.14198/ihse.2019.14.Proc4.54

\footnotetext{
Corresponding author. Department of Basic Medical Sciences, Neuroscience and Sense Organs, School of Medicine, University of Study of Bari, Lungomare Starita 1, 70123 Bari (BA). Italy. http://orcid.org/0000-0002-5023-3721

E-mail: gianpiero.greco@uniba.it

Supplementary Issue: Spring Conferences of Sports Science. Costa Blanca Sports Science Events, 14-15 June 2019. Alicante, Spain.

JOURNAL OF HUMAN SPORT \& EXERCISE ISSN 1988-5202

(c) Faculty of Education. University of Alicante

doi:10.14198/jhse.2019.14.Proc4.54
}

S916 | 2019 | Proc4 | VOLUME 14

C 2019 University of Alicante 


\section{INTRODUCTION}

Physical activity has been demonstrated to play a preventive role in terms of the risk of developing cancer (Friedenreich \& Orenstein, 2002; Willer, 2003) and it is also emerging as a major tool to improve the quality of life and survival of patients with cancer (Jacobs, 2017). Data show that higher levels of physical activity are associated with lower overall cancer mortality (Moore et al., 2016; Thompson, 1994). Cancer patients and survivors, however, bring with them physiological and psychological side effects including muscular atrophy, weight changes, lowered aerobic capacity, decreased strength and flexibility, nausea, fatigue, depression, and an overall decrease in the quality of life (Courneya \& Friedenreich, 1997; Graydon, 1994; Lucía, Earnest, \& Pérez, 2003; Miller et al., 2016).

Cancer-related fatigue is the most common side effect of cancer and cancer treatment (Dimeo, 2001; Lucía et al., 2003). In addition, the sedentary habits usually recommended by the biomedical staff and the family to protect the patient may lead to the development of the self-perpetuating fatigue cycle, which promotes muscular catabolism and chronic fatigue (Dimeo, 2001; Lucía et al., 2003). Physical training breaks this downward cycle and diminishes cancer-related fatigue (Lucia et al., 2003). Indeed, studies demonstrated that exercise both during and after treatment is an effective tool to improve functional capacity, strength, functional mobility, fatigue, psychological well-being and health-related quality of life in cancer patients and survivors (Cramp \& Byron-Daniel, 2012; Dash et al., 2016; Hojan et al., 2016; Van Vulpen et al., 2016).

Benefits of resistance training and combined aerobic and resistance training in cancer patients and survivors are known: they result improvements in many areas including functional mobility (Blair et al., 2014; Herrero et al., 2006), flexibility (Cheema \& Gaul, 2006; Kolden et al., 2002) and fatigue (Dimeo, Schwartz, Wesel, Voigt, \& Thiel, 2008; Travier et al., 2015), which were also analysed in present study. Nevertheless, the benefits of physical training may vary according to the type of cancer and treatment, the stage of disease; the mode, intensity, and duration of the exercise program, and the current lifestyle of the patient (Knols, Aaronson, Uebelhart, Fransen, \& Aufdemkampe, 2005). For this reason, we designed an intervention study to examine the effects of the manipulation of specific training variables, because few longitudinal studies analysed this topic (Courneya et al., 2003; Dimeo, Rumberger, \& Keul, 1998; Durak \& Lilly, 1998; McKenzie \& Kalda, 2003; Segal et al., 2003).

Therefore, the purpose of this study was to investigate the effects of an 8-week multilateral training program on perceived fatigue, lower back flexibility, balance and task specific functional mobility in cancer patients. We hypothesized that physical and psychological fitness would enhance with multilateral intervention.

\section{MATERIALS AND METHODS}

\section{Participants}

This study utilized a randomized and controlled pretest-posttest research design, in order to collect data before and again following the eight-week treatment and compare the difference between groups. Before entering the study, informed consent was obtained from each participant. This study did not involve human individuals from a clinical or therapeutic point of view. A human sample was used, without medical contraindications, to examine only the influence of physical exercise as an educational means to improve lifestyles and self-efficacy. The procedures followed were in accordance with the ethical standards of the responsible institutional committee on human experimentation and with the Helsinki Declaration. 
A preliminary screening for participants selection was performed in the medical database of the Oncology Department, Haematology Unit, "Giovanni Paolo II" of Bari (Italy). Patients were contacted by telephone (February 2019) and a preliminary medical examination and the completion of a lifestyle history questionnaire were performed prior to the star of the study (March 2019). After the corresponding oncologist provided consent, patients were deemed eligible for the study if they did not present the following contraindications to physical exercise for patients with cancer (Ehrman, Gordon, Visich, \& Keteyian, 2019): 1) Hemoglobin <10.0 $\mathrm{g} \mathrm{dL}^{-1}$; 2) White blood cells $<3000 / \mathrm{mL}$; 3) Neutrophil count $<0.510^{9} \mathrm{~mL}^{-1}$; 4) Platelet count $<5010^{9} \mathrm{~mL}^{-1} ; 5$ ) Fever $>38{ }^{\circ} \mathrm{C}$; 6) Unsteady gait (ataxia); 7) Cachexia or loss of $>35 \%$ of premorbid weight; 8 ) Limiting dyspnea with exertion; 9) Bone pain; 10) Severe nausea; 11) Extensive skeletal metastases.

Twenty participants that met all the above-mentioned eligibility criteria were pair-matched based on age and then randomly assigned to an experimental group $(n=10$; mean age, $53.3 \pm 19.2$ years; body mass, $63.3 \pm$ $12.8 \mathrm{~kg}$; height, $1.62 \pm 0.1 \mathrm{~m}$ ) that performed a progressive multilateral training or a wait-list control group (n = 10; mean age, $52.0 \pm 15.7$ years; body mass, $60.9 \pm 10.3 \mathrm{~kg}$; height, $1.64 \pm 0.1 \mathrm{~m})$. Patients were diagnosed the following cancer types: breast cancer $(n=3)$, Hodgkin's lymphoma $(n=6)$, Non-Hodgkin's lymphoma $(n=8)$, multiple myeloma $(n=1)$, colon cancer $(n=1)$, and polycythemia vera $(n=1)$. At the start of the study, almost all patients $(n=18)$ were on therapy. The study was carried out between the months of March and May 2019.

\section{Testing procedures}

Groups assessments were made at baseline (pre-test) and repeated after 8 weeks (post-test). The following measures were collected: (1) cancer-related fatigue (0-10 subjective rating scale), (2) lower back flexibility (trunk lateral flexibility test), (3) static balance (stork balance stand test), and (4) functional performance (30second chair stand test). All participants were tested in a gym located inside the Oncological Institute. One week before pre-test, two familiarizations sessions were held. Initial and final test measurements were made at the same time of day and under the same experimental conditions. All measurements were performed and supervised by the same exercise professionals, that is Adapted Physical Education Specialists.

\section{Cancer-related fatigue subjective rating}

Fatigue is a symptom affected by multiple biological and psychosocial factors. When assessing cancerrelated fatigue, therefore, we need to include both subjective and objective data. To assess cancer-related fatigue, the subjects were asked two questions (Portenoy \& Itri, 1999) to help assess the severity of fatigue and its effect over time: 1) are you experiencing any fatigue? 2) If so, how severe has it been, on average, during the past week? (If fatigue is present a simple $0-10$ rating scale can be used, that is, $0-3$ is mild fatigue, 4-6 moderate, and 7-10 severe). All patients had been familiarized with this scale prior to the commencement of the study and followed standardized instructions for rating perceived exertion. Scores was collected and recorded before and after the eight-week intervention period.

Trunk lateral flexibility test

Trunk flexibility is important in the ability to carry out activities of daily living. Estimates of trunk flexibility frequently affect diagnostic, prognostic, and therapeutic decisions for a variety of health disorders (ACSM, 2018). Each participant was measured for trunk lateral range of motion using a tape measure. The same tape measurement procedure has been reported previously and has high levels of reliability with repeated measures (ICC $=0.98)$ (Frost, Stuckey, Smalley, \& Dorman, 1982). Subjects first underwent a 15-second static stretch in the lateral trunk motion and then were tested. Subjects stood on the floor with arms in the neutral position, heels together, knees and back straight. Then they bent toward the right/left with elbow and fingers straight and attached hand on their lateral side of leg. The distance $(\mathrm{cm})$ between the tip of third finger 
and the floor was measured three times and the lower measure was used in the analyses. The test-retest reliability reported a high reliability for this test (ICC $=0.95)$.

\section{Stork balance stand test}

This test evaluates postural static balance (McCurdy \& Langford, 2006). Subject were tested on the dominant and non- dominant leg. The participants were instructed to lift and hold the contralateral leg against the medial side of the knee of the stance leg while keeping his hands on the iliac crests. The trial ended when the heel of the involved leg touched the floor, the hands came off the hips, or the opposite foot was removed from the stance leg. This test was conducted with eyes opened only. The subjects performed three attempts and the best time (sec.) was recorded for analysis. High test-retest reliability has been reported for this test with an intraclass correlation coefficient (ICC) of 0.92.

\section{0-second chair stand test}

This test is one of the most important functional evaluation clinical tests because it measures lower body strength and relates it to the most demanding daily life activities (e.g., climbing stairs, getting out of a chair or bathtub or rising from a horizontal position) (Macfarlane, Chou, Cheng, \& Chi, 2006). It is also able to assess functional fitness levels (Wong \& Cheung, 2005) and the fatigue effect caused by the number of sitto-stand repetitions. It consists of standing up and sitting down from a chair as many times as possible $(\mathrm{n})$ within 30 seconds. A standard chair (with a seat height of $40 \mathrm{~cm}$ ) without a backrest but with armrests was used. Initially, subjects were seated on the chair with their back in an upright position. They were instructed to look straight forward and to rise after the "1, 2, 3, go" command at their own preferred speed with their arms folded across their chest. All trials were performed using the same chair and with similar ambient conditions.

\section{Multilateral intervention program}

Currently there is no evidence supporting a different training response to exercise in the patient with cancer from that in the general adult population. Accordingly, in present study the American College of Sports Medicine guidelines for cancer survivors were followed (Schmitz et al., 2010). All sessions were conducted under direct supervision of exercise professionals, specialists in Adapted Physical Education, to ensure safety, proper intensity, and appropriate exercise technique (Greco, Settimo \& Fischetti, 2018). Additionally, the mode, frequency, intensity, duration, and progression in an individual exercise log were recorded to ensure adequate training. The 8-week study period followed the initial data collection, with the experimental group that performed an intervention program consisting of twice-per-week exercise sessions lasting 60 minutes each. Every single exercise session was divided into a 10-min warm-up (i.e., postural education exercises and stretching of all major muscle groups), a 40-min main exercise period (i.e., aerobic exercise, resistance training), and a 10-min cooldown period (i.e., stretching again and/or postural education exercises).

During the main exercise period, cardiorespiratory training consisted of progressive 30-min of walking and stationary bike at an intensity that ranged from $40 \%$ to $80 \%$ of heart rate reserve. Heart rate was monitored by the subjects and the exercise professionals during training using a Polar heart rate monitor (Target model, Kempele, Finland). The duration of the aerobic exercise was initially $16 \mathrm{~min}$ and was divided equally among the two exercise modalities in a rotational order. Based on the recommendations in the literature (Jacobs, 2017; Schmitz et al., 2010), the aerobic-exercise period was increased by 2 min a week, such that it was 30 min during week 8. 
Resistance training consisted of 10-min of exercises with free weights and/or resistance bands, at an intensity ranging from $50 \%$ to $70 \%$ of $1 \mathrm{RM}$ for lifts involving the lower body and from $40 \%$ to $70 \%$ of $1 \mathrm{RM}$ for lifts involving the upper body. 8-10 exercises for major muscle groups, 1 or 2 sets of 8 to 12 reps, and a rest 1-3 min between exercises and sets, were performed with a gradual increase in resistance $(1-2 \mathrm{~kg})$ following two consecutive symptom-free sessions.

Flexibility was trained before and after main period by stretching exercises performed maximally on all major muscle groups ( $1-3$ sets per muscle group) but avoiding pain, especially in joints. Duration was gradual from 10 to $30 \mathrm{~s}$ per stretch, repeating one to three times for a total of $60 \mathrm{~s}$ per stretch. Following approval from surgeon, special attention was given to shoulder mobility stretches in breast cancer survivors.

Postural education exercises were carried out both in the warm-up and cooldown period, and consisted of breathing, proprioception and balance exercises. In some sessions a Pilates mat workout has also been integrated.

Finally, the exercise program focused on physical activities that use large muscle groups rather than small groups, since most daily living tasks depend on these large muscle groups. Session design and exercises were modified according to the acute or chronic treatment effects of surgery, chemo-therapy, or radiotherapy.

\section{Statistical analyses}

Normality of all parametric variables was tested using Shapiro-Wilk test procedure. A multivariate analysis of variance (MANOVA) was used to detect differences between the study groups in all baseline variables. Training-related effects were assessed by 2-way analyses of variance (ANOVA) with repeated measures (group $x$ time). When 'Time x Group' interactions reached the level of significance, group-specific post hoc tests (i.e., paired t-tests) were conducted to identify the significant comparisons.

Cohen's $d$ effect size was calculated as post-training mean minus pre-training mean divided by pooled SD before and after training, and interpreted as small, moderate and large effects defined as $0.20,0.50$, and 0.80 , respectively (Cohen, 1992). The reliabilities of the physiological measures were assessed using the intraclass correlation coefficients; scores from 0.8 to 0.9 were considered as good, while values above $>0.9$ were considered as high (Vincent \& Weir, 2012).

All analyses were conducted with SAS JMP® Statistics (Version <14.1>, SAS Institute Inc., Cary, NC, USA, 2018) and the data are presented as group mean values and standard deviations. An alpha level of $p<0.05$ was considered statistically significant.

\section{RESULTS}

Adherence to training averaged $95.5 \pm 2.3 \%$. All participants completed the multilateral intervention and no major adverse effect and no major health problem were noted over the 8-week period. Both groups did not differ significantly at baseline in age, anthropometric characteristics, as well as in the dependent measures $(p>0.05)$. Changes and statistical data in the dependent variables over 8-week multilateral intervention program are reported in Table 1. 
Table 1. Changes in dependent measures after 8-week multilateral training intervention

\begin{tabular}{lcccccc}
\hline & \multicolumn{3}{c}{$\begin{array}{c}\text { Experimental group } \\
(\mathbf{n}=\mathbf{1 0})\end{array}$} & \multicolumn{3}{c}{$\begin{array}{c}\text { Control group } \\
(\mathbf{n}=10)\end{array}$} \\
\hline Variables & Pre-test & Post-test & $\boldsymbol{\Delta}$ & Pre-test & Post-test & \multicolumn{1}{c}{$\boldsymbol{\Delta}$} \\
\hline Fatigue rating scale & $4.7(0.7)$ & $2.8(1.0) \dagger^{*}$ & -1.9 & $4.3(1.1)$ & $4.2(1.0)$ & -0.1 \\
Trunk flexibility L (cm) & $14.8(3.1)$ & $12.3(2.9) \dagger^{*}$ & -2.5 & $15.5(3.5)$ & $15.3(3.3)$ & -0.2 \\
Trunk flexibility R (cm) & $15.3(3.2)$ & $13.1(3.1) \dagger^{*}$ & -2.2 & $14.9(2.4)$ & $14.6(2.1)$ & -0.3 \\
Stork balance L (s) & $33.5(22.3)$ & $47.4(25.8) \dagger^{*}$ & 13.9 & $32.8(15.3)$ & $32.2(15.4)$ & -0.6 \\
Stork balance R (s) & $36.6(18.9)$ & $46.9(21.9) \dagger^{*}$ & 24.3 & $43.2(21.1)$ & $43.1(21.5)$ & -0.1 \\
30-s chair $(\mathrm{n})$ & $14.5(3.5)$ & $18.7(3.5) \dagger^{*}$ & 4.2 & $14.3(3.4)$ & $13.9(5.3)$ & -0.4 \\
\hline
\end{tabular}

Note: values are presented as mean $( \pm S D) ; \Delta$ : pre-post mean difference; $L=$ left; $R=$ =right. *Significantly different from pre-test $(p<$ 0.01). + Significant 'Time $x$ Group' interaction = significant effect of the multilateral intervention $(p<0.01)$.

After 8 weeks, a 'Time $x$ Group' interaction was observed for the cancer-related fatigue rating scale $(p<$ $0.001)$. The experimental group showed decreased scores than control group with statistically significant within-group changes $(p<0.001 ; d=1.22)$.

Over the 8-week intervention, group by time interactions were observed for all physical and functional fitness measures $(p<0.01)$. The experimental group showed highly significant improvements than control group with changes from pre- to post-intervention for trunk lateral flexibility test (Left side: $p<0.001, d=1.44$; Right side: $p<0.01, d=1.55$ ), stork balance stand test (Left leg: $p<0.001, d=1.32$; Right leg: $p<0.001, d=1.18$ ) and 30 -second chair stand test $(p<0.001 ; d=1.06)$.

\section{DISCUSSION}

In keeping with recent trends in exercise prescription to encourage even modest levels of physical activity for health benefits, this study evaluated the effect of combined aerobic, resistance and postural exercises. It has been found that 8-week of a physical exercise intervention program significantly improved the cancer-related fatigue, lower back flexibility, static balance and task specific functional mobility in cancer patients. This is in agree with several other studies that have shown the benefits of combined aerobic and resistance training in cancer patients and survivors, reporting improvements in functional fitness levels and psychological wellbeing (Blair et al., 2014; Cheema \& Gaul, 2006; Courneya et al., 2007; Dimeo et al., 2008; Herrero et al., 2006; Kolden et al., 2002; Travier et al., 2015).

There is a growing body of research demonstrating that physical exercise performed both during and after treatment is an effective tool to achieve health benefits in terms of functional performance, fatigue, psychological well-being, and health-related quality of life in cancer patients and survivors (Burnham \& Wilcox, 2002; Cramp \& Byron-Daniel, 2012; Dash et al., 2016; Dimeo et al., 1998; Hojan et al., 2016; Oldervoll, Kaasa, Knobel, \& Loge, 2003; Van Vulpen et al., 2016). However, the benefits of physical training may vary according to the type of cancer and treatment, and the current lifestyle of the patient (Knols et al., 2005). In the present study, participants were affected by different types of cancer (breast cancer, Hodgkin's lymphoma, non-Hodgkin's lymphoma, multiple myeloma, colon cancer, and polycythemia vera) and all showed significant improvements in physiological measures. Multilateral training has once again demonstrated its effectiveness on physical and psychological fitness in the population (Fischetti, Cataldi, Di Terlizzi, \& Greco, 2019; Fischetti, Cataldi, \& Greco, 2019; Fischetti \& Greco, 2017; Fischetti, Latino, Cataldi, 
\& Greco, 2019; Greco, Cataldi, \& Fischetti, 2019). Participants improved balance and, consequently, they will have a lower risk of falls and fractures, as with greater strength in the legs they will be able to carry out the activities of daily life more easily without being overwhelmed by fatigue.

Cancer-related fatigue is the most common side effect of cancer treatment, and the sedentary habits usually recommended by the biomedical staff and the family to protect the patient may lead to higher level of catabolic processes at all levels (i.e., physical, emotional, social) (Dimeo, 2001; Lucía et al., 2003). Our combined exercise program, made by exercise professionals, not only allowed to increase the functional and physical fitness levels of all cancer patients, increasing the fatigue resistance, but also reduced the subjective perception of perceived exertion. However, the combined results of increased lower body strength and endurance showed by the 30-second chair stand test could partially explain the reduced levels of perceived fatigue observed in the present study and in other study (Segal et al., 2003). In any case, we have given cancer patients the opportunity to improve their quality of life, as also shown by previous studies (Cramp \& Byron-Daniel, 2012; Dash et al., 2016; Hojan et al., 2016; Van Vulpen et al., 2016), and we confirmed the physical exercise as a major prevention tool.

Accordingly, we can state that a few weeks of regular exercise might be sufficient to start helping patients and survivors cope with the anti-cancer treatment and its long lasting, deleterious side effects. However, most of these results could be the consequence of the high level of deconditioning of cancer patients, such that any small stimulus such as a short exercise program (i.e., eight weeks) may lead to the partial recovery of the patient's normal physiological and psychological characteristics. So, more work is needed to elucidate the long-term beneficial effects of combined exercise training in cancer patients.

Our study presents some limitations must be known. The small number of patients with different types of cancer did not allow to draw valid conclusions based on the results obtained. Furthermore, in this study it was not possible to follow the recommendations by ACSM (Schmitz et al., 2010), that is $\geq 150 \mathrm{~min} / \mathrm{week}$ of exercise at moderate intensity or $\geq 75 \mathrm{~min} /$ week of exercise at vigorous intensity due to organizational reasons. Nevertheless, by findings we may provide new indications on training loads for cancer patients.

\section{CONCLUSIONS}

To our knowledge, this study is the first investigation to attempt to identify the effects of combined aerobic, resistance and postural exercises on both physiological and psychological functioning in cancer patients. In particular, this study demonstrated the effectiveness of exercise on perceived cancer-related fatigue, confirming the physical exercise as a major cancer prevention tool. Furthermore, physical fitness and functional capacity were enhanced, providing an important support to cancer patients undergoing treatment. In this way, a multilateral approach could prevent and minimize physical inactivity, fatigue, muscle wasting, and loss of energy. For this reason, exercise professionals, specialists in Adapted Physical Education, need to be involved in the biomedical staff because they are the only ones able to manipulate the training variables like volume, intensity or load, duration of rest periods, frequency of training, and training velocity for the health and well-being benefit of the special populations.

\section{FUNDING}

No sources of funding were used to assist in the preparation of this manuscript. 


\section{CONFLICT OF INTEREST STATEMENT}

The authors declared no potential conflicts of interest with respect to the research, authorship, and/or publication of this article.

\section{AUTHORS' CONTRIBUTIONS}

SC designed the study, interpreted the data and wrote the manuscript. FL collected and interpreted the data and wrote the manuscript. GG carried out the statistical analysis, interpreted the data and revised the manuscript. FF designed the study, interpreted the data and revised the manuscript. All authors contributed intellectually to the manuscript, and all authors have read the manuscript and approved the submission.

\section{REFERENCES}

American College of Sports Medicine. (2018). ACSM's guidelines for exercise testing and prescription (10th ed.). Philadelphia: Wolters Kluwer. pp. 102-110.

Blair, C. K., Morey, M. C., Desmond, R. A., Cohen, H. J., Sloane, R., Snyder, D. C., \& DemarkWahnefried, W. (2014). Light-intensity activity attenuates functional decline in older cancer survivors. Medicine and science in sports and exercise, 46(7), 1375. https://doi.org/10.1249/mss.0000000000000241

Burnham, T. R., \& Wilcox, A. (2002). Effects of exercise on physiological and psychological variables in cancer survivors. Medicine \& Science in Sports \& Exercise, 34(12), 1863-1867. https://doi.org/10.1097/00005768-200212000-00001

Cheema, B. S. B., \& Gaul, C. A. (2006). Full-body exercise training improves fitness and quality of life in survivors of breast cancer. Journal of strength and conditioning research, 20(1), 14. https://doi.org/10.1519/00124278-200602000-00003

Cohen, J. (1988). Statistical power analysis for the behavioral sciences. 2nd edition. Hillsdale, NJ: L. Lawrence Earlbaum Associates.

Courneya, K. S., \& Friedenreich, C. M. (1997). Determinants of exercise during colorectal cancer treatment: an application of the theory of planned behavior. Oncology nursing forum, 24, (10), 17151723.

Courneya, K. S., Mackey, J. R., Bell, G. J., Jones, L. W., Field, C. J., \& Fairey, A. S. (2003). Randomized controlled trial of exercise training in postmenopausal breast cancer survivors: cardiopulmonary and quality of life outcomes. Journal of clinical oncology, 21(9), 1660-1668. https://doi.org/10.1200/jco.2003.04.093

Courneya, K. S., Segal, R. J., Mackey, J. R., Gelmon, K., Reid, R. D., Friedenreich, C. M., ... \& Yasui, Y. (2007). Effects of aerobic and resistance exercise in breast cancer patients receiving adjuvant chemotherapy: a multicenter randomized controlled trial. Journal of clinical oncology, 25(28), 43964404. https://doi.org/10.1200/jc0.2006.08.2024

Cramp, F. A., \& Byron-Daniel, J. Z. (2012). Exercise for the management of cancer related fatigue in adults. Cochrane database of systematic reviews, 11(131). https://doi.org/10.1002/14651858.cd006145.pub2

Dash, C., Randolph-Jackson, P. D., Isaacs, C., Mills, M., Makambi, K., Watkins, V. V., \& AdamsCampbell, L. L. (2016). An exercise trial to reduce cancer related fatigue in African American breast cancer patients undergoing radiation therapy: Design, rationale, and methods. Contemporary clinical trials, 47, 153-157. https://doi.org/10.1016/i.cct.2016.01.004 
Dimeo, F. C. (2001). Effects of exercise on cancer-related fatigue. Cancer: Interdisciplinary International Journal of the American Cancer Society, 92(S6), 1689-1693. https://doi.org/10.1002/10970142(20010915)92:6+<1689::aid-cncr1498>3.0.c0;2-h

Dimeo, F., Rumberger, B. G., \& Keul, J. (1998). Aerobic exercise as therapy for cancer fatigue. Medicine and science in sports and exercise, 30(4), 475-478. https://doi.org/10.1097/00005768-19980400000001

Dimeo, F., Schwartz, S., Wesel, N., Voigt, A., \& Thiel, E. (2008). Effects of an endurance and resistance exercise program on persistent cancer-related fatigue after treatment. Annals of oncology, 19(8), 1495-1499. https://doi.org/10.1093/annonc/mdn068

Durak, E. P., \& Lilly, P. C. (1998). The application of an exercise and wellness program for cancer patients: a preliminary outcomes report. The Journal of Strength \& Conditioning Research, 12(1), 36. https://doi.org/10.1519/00124278-199802000-00001

Ehrman, J., Gordon, P., Visich, P., \& Keteyian, S. (2019). Clinical Exercise Physiology (4th ed). Champaign, IL: Human Kinetics. p. 382.

Fischetti, F., Cataldi, S., Di Terlizzi, P.G., \& Greco, G. (2019). Multilateral methodology in physical education improves coping skills, resilience and physical fitness in drug addicts. Journal of Human Sport and Exercise. https://doi.org/10.14198/ihse.2020.152.11

Fischetti, F., Cataldi, S., \& Greco, G. (2019). A Combined Plyometric and Resistance Training Program Improves Fitness Performance in 12 to 14-years-old Boys. Sport Sciences for Health. https://doi.org/10.1007/s11332-019-00560-2

Fischetti, F., \& Greco, G. (2017). Multilateral methods in Physical Education improve physical capacity and motor skills performance of the youth. Journal of Physical Education and Sport, 17(Suppl 4), 2161-2168. https://doi.org/10.7752/jpes.2017.s4223.

Fischetti, F., Latino, F., Cataldi, S., \& Greco, G. (2019). Gender Differences in Body Image Dissatisfaction: The Role of Physical Education and Sport. Journal of Human Sport and Exercise. https://doi.org/10.14198/ihse.2020.152.01

Friedenreich, C. M., \& Orenstein, M. R. (2002). Physical activity and cancer prevention: etiologic evidence and biological mechanisms. The Journal of nutrition, 132(11), 3456S-3464S. https://doi.org/10.1093/jn/132.11.3456s

Frost, M., Stuckey, S., Smalley, L. A., \& Dorman, G. (1982). Reliability of measuring trunk motions in centimeters. Physical therapy, 62(10), 1431-1437. https://doi.org/10.1093/pt//62.10.1431

Graydon, J. E. (1994). Women with breast cancer: their quality of life following a course of radiation therapy. Journal of Advanced Nursing, 19(4), 617-622. https://doi.org/10.1111/j.13652648.1994.tb01131.x

Greco, G., Cataldi, S., \& Fischetti, F. (2019). Effectiveness of a Short After-School Intervention on Physical Fitness in School-Aged Children. Journal of Theories and Research in Education.14(1), 143-164. https://doi.org/10.6092/issn.1970-2221/9217

Greco, G., Settimo, M., \& Fischetti, F. (2018). Relationship between the correct running technique and lower back well-being perceived by the practitioner. Journal of Physical Education and Sport,18(3), 1796-1800.

Herrero, F., San Juan, A. F., Fleck, S. J., Balmer, J., Perez, M., Canete, S., ... Lucia, A. (2006). Combined aerobic and resistance training in breast cancer survivors: A randomized, controlled pilot trial. International Journal of Sports Medicine, 27(7), 573-580. https://doi.org/10.1055/s-2005-865848

Hojan, K., Kwiatkowska-Borowczyk, E., Leporowska, E., Gorecki, M., Ozga-Majchrzak, O., Milecki, T., \& Milecki, P. (2016). Physical exercise for functional capacity, blood immune function, fatigue, and quality of life in high-risk prostate cancer patients during radiotherapy: a prospective, randomized 
clinical study. European journal of physical and rehabilitation medicine, 52(4), 489-501. https://doi.org/10.1016/j.rehab.2014.03.1350

Jacobs, P. (Ed.). (2017). NSCA's Essentials of Training Special Populations. Champaign, IL: Human Kinetics.

Knols, R., Aaronson, N. K., Uebelhart, D., Fransen, J., \& Aufdemkampe, G. (2005). Physical exercise in cancer patients during and after medical treatment: a systematic review of randomized and controlled clinical trials. Journal of clinical oncology, 23(16), 3830-3842. https://doi.org/10.1200/jco.2005.02.148

Kolden, G. G., Strauman, T. J., Ward, A., Kuta, J., Woods, T. E., Schneider, K. L., ... \& Kalin, N. H. (2002). A pilot study of group exercise training (GET) for women with primary breast cancer: feasibility and health benefits. Psycho-Oncology: Journal of the Psychological, Social and Behavioral Dimensions of Cancer, 11(5), 447-456. https://doi.org/10.1002/pon.591

Lucía, A., Earnest, C., \& Pérez, M. (2003). Cancer-related fatigue: can exercise physiology assist oncologists? The lancet oncology, 4(10), 616-625. https://doi.org/10.1016/s1470-2045(03)01221-x

Macfarlane, D. J., Chou, K. L., Cheng, Y. H., \& Chi, I. (2006). Validity and normative data for thirtysecond chair stand test in elderly community-dwelling Hong Kong Chinese. American Journal of Human Biology: The Official Journal of the Human Biology Association, 18(3), 418-421. https://doi.org/10.1002/ajhb.20503

McCurdy, K., \& Langford, G. (2006). The relationship between maximum unilateral squat strength and balance in young adult men and women. Journal of sports science \& medicine, 5(2), 282.

McKenzie, D. C., \& Kalda, A. L. (2003). Effect of upper extremity exercise on secondary lymphedema in breast cancer patients: a pilot study. Journal of clinical oncology, 21(3), 463-466. https://doi.org/10.1200/jco.2003.04.069

Miller, K. D., Siegel, R. L., Lin, C. C., Mariotto, A. B., Kramer, J. L., Rowland, J. H., ... \& Jemal, A. (2016). Cancer treatment and survivorship statistics, 2016. CA: a cancer journal for clinicians, 66(4), 271 289. https://doi.org/10.3322/caac. 21349

Moore, S. C., Lee, I. M., Weiderpass, E., Campbell, P. T., Sampson, J. N., Kitahara, C. M., ... \& Adami, H. O. (2016). Association of leisure-time physical activity with risk of 26 types of cancer in 1.44 million adults. JAMA internal medicine, 176(6), 816-825. https://doi.org/10.1001/jamainternmed.2016.1548

Oldervoll, L. M., Kaasa, S., Knobel, H., \& Loge, J. H. (2003). Exercise reduces fatigue in chronic fatigued Hodgkins disease survivors-results from a pilot study. European Journal of Cancer, 39(1), 57-63. https://doi.org/10.1016/s0959-8049(02)00483-5

Portenoy, R. K., \& Itri, L. M. (1999). Cancer-related fatigue: guidelines for evaluation and management. The oncologist, 4(1), 1-10.

Schmitz, K. H., Courneya, K. S., Matthews, C., Demark-Wahnefried, W., Galvão, D. A., Pinto, B. M., ... \& Schneider, C. M. (2010). American College of Sports Medicine roundtable on exercise guidelines for cancer survivors. Medicine \& Science in Sports \& Exercise, 42(7), 1409-1426. https://doi.org/10.1249/mss.0b013e3181e0c112

Segal, R. J., Reid, R. D., Courneya, K. S., Malone, S. C., Parliament, M. B., Scott, C. G., ... \& Wells, G. A. (2003). Resistance exercise in men receiving androgen deprivation therapy for prostate cancer. Journal of Clinical Oncology, 21(9), 1653-1659. https://doi.org/10.1200/jco.2003.09.534

Thompson, W. G. (1994). Exercise and health: fact or hype? Southern medical journal, 87(5), 567-574.

Travier, N., Velthuis, M. J., Bisschop, C. N. S., van den Buijs, B., Monninkhof, E. M., Backx, F., ... \& de Roos, M. A. (2015). Effects of an 18-week exercise programme started early during breast cancer treatment: a randomised controlled trial. BMC medicine, 13(1), 121. https://doi.org/10.1186/s12916$\underline{015-0362-z}$ 
Van Vulpen, J., Velthuis, M. J., Steins, C. B., Travier, N., Van, B. D. B., Backx, F. J., ... \& De, M. R. (2016). Effects of an Exercise Program in Colon Cancer Patients undergoing Chemotherapy. Medicine and science in sports and exercise, 48(5), 767-775. https://doi.org/10.1249/mss.0000000000000855

Vincent, W., \& Weir, J. P. (2012). Statistics in Kinesiology (4th Ed). Champaign, IL: Human Kinetics.

Willer, A. (2003). Reduction of the individual cancer risk by physical exercise. Oncology Research and Treatment, 26(3), 283-289. https://doi.org/10.1159/000071626

Wong, K.Y.A., \& Cheung, S.Y. (2005). Physical activity level and functional fitness of older women in Hong Kong. Research Quarterly for Exercise and Sport, 76, 119 - 120.

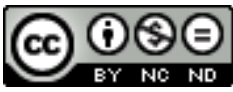

This work is licensed under a Attribution-NonCommercial-NoDerivatives 4.0 International (CC BY-NC-ND 4.0). 